\title{
The Effects of Discourse Types on the Use of English Articles by Korean Learners of English: Oral vs. Written Narratives
}

\author{
Juyeon Lee ${ }^{1}$ \\ ${ }^{1}$ Graduate School of Interpretation and Translation, Hankuk University of Foreign Studies, Seoul, Korea \\ Correspondence: Juyeon Lee, Graduate School of Interpretation and Translation, Hankuk University of Foreign \\ Studies, 107, Imun-Ro, Dongdaemun-Gu, Seoul, Korea. Tel: 82-10-9932-6769. E-mail: juliajustin@gmail.com
}

\author{
Received: May 7, 2013 Accepted: May 28, 2013 Online Published: July 4, 2013 \\ doi:10.5539/elt.v6n8p33 URL: http://dx.doi.org/10.5539/elt.v6n8p33
}

\begin{abstract}
Learning to use English articles appropriately has been considered a challenging task for L2 learners of English, especially when their L1s do not have a similar article system. Much research has been conducted in this area, but little has been studied about the effects of discourse types (i.e., spoken discourse versus written discourse) on the accurate production of English articles by L2 learners. The present study examined how Korean learners of English at distinct proficiency levels employed articles in oral narratives compared to written narratives. The results showed that the cognitive and performance constraints associated with spontaneous oral speech hindered learners from producing articles accurately. Furthermore, the effects of discourse types were found to be greater on the indefinite article, whose usage is considered more complex than the definite article. Concerning the proficiency levels, the intermediate learners exhibited patterns that are indicative of a considerable gap between implicit and explicit knowledge of English articles while the advanced learners seem to have stabilized in their use of articles. The findings of this study suggest that writing activities can be beneficial for learners at the beginning levels to increase the awareness of the English article system. For more proficient learners, speaking activities can be used to promote a more accurate production of articles in both speech and writing by utilizing their explicit knowledge of English articles.
\end{abstract}

Keywords: English article system, discourse effect, Korean learners of English, L2 pedagogy of articles

\section{Introduction}

In the field of second language acquisition (SLA), it has been documented that the mastery of the English article system by English language learners (ELLs) is a challenging task (Butler, 2002; Ekiert, 2010; Liu \& Gleason, 2002; Trenkic, 2007, Young, 1996, among others). As Master (1997) points out, the articles are among the most frequently used English words. Therefore, learners are likely to be exposed to abundant input that contains a variety of uses of articles. Nevertheless, successful acquisition of the article system by second language (L2) learners seems to be difficult, if not impossible (e.g., Master, 1990; Mizuno, 1999; Park, 2006; Parrish, 1987).

Much has been studied in this area, but the types of data collected from the learners have been relatively limited to oral production data and experimental data. For instance, several studies collected oral language for the purpose of analysis of article use (Huebner, 1979; Parrish, 1987; Robertson, 2000, Tarone \& Parish, 1988; Thomas, 1989; Trenkic, 2007; White, 2003; Zdorenko \& Paradis, 2008). Other scholars resorted to explicit data collection instruments such as multiple choices, forced-elicitation tasks, fill-in-the-blanks, and dictations to investigate L2 acquisition of English articles. In contrast, only a few studies have been documented about how learners of English use articles in their writing. Furthermore, little research has been conducted about different patterns of L2 article use between speaking and writing.

This study compared article use in oral narratives and written narratives. The purpose of the comparisons is to investigate what aspects of article use would benefit most from the absence of time and cognitive constraints. In spontaneous oral production, L2 learners are under pressure to attend to accuracy and fluency simultaneously. Without such pressure, learners may be able to utilize their conscious knowledge of English and direct their attention to grammatical accuracy with regard to article use. Thus, it can be assumed that the overall accuracy in the use of articles would be better in written production, and this study aimed to explore in more detail how the different discourses of speaking and writing would affect patterns of article use among Korean learners of English at different levels of proficiency. 


\section{Background of the Study}

\subsection{Article Production in Oral Discourse}

SLA researchers became interested in the topic of L2 acquisition of the English article system in the 1980s and many of them collected oral data to investigate patterns of article use by L2 learners of English from various L1 backgrounds. The flourishing research on L2 use of English articles was in part attributed to Huebner (1979) who proposed a method of analysis called "dynamic paradigm" that scholars found useful and effective in analyzing how L2 learners use articles in spontaneous production.

Huebner collected an oral corpus produced over a period of 12 months by a 23 -year-old male Hmong refugee from Laos, living in Honolulu and learning English in a natural setting without formal instruction. Based on the assumption of interlanguage that "language is systematic but dynamic, and that variation is the precursor to change" (p. 22), Huebner designed the dynamic paradigm of English articles to examine variation in interlanguage. This paradigm accounts for article use in all pre-noun positions in terms of Specific Referent (SR) and Assumed Known to Hearer (HK). By applying this model of analysis to the oral corpus data, Huebner showed that the participant's hypotheses about the article system were under continuous revision. Huebner's dynamic paradigm has had a significant influence on subsequent studies that described patterns of article use by L2 speakers of English (Parrish, 1987; Tarone \& Parrish, 1988; Thomas, 1989; Young, 1996). His diagram provided a simple but comprehensive frame of analysis that made it possible for researchers to consider both the aspect of specificity of a referent and the aspect of the hearer's understanding of a referent in their analysis of article usage.

One of the studies that utilized Heubner's (1979) semantic paradigm to investigate L2 article use was conducted by Tarone and Parrish (1988). In particular, the researchers studied how different task types influence English article production by L2 learners of English. The three tasks were: (1) a written grammaticality judgment task where the participants were asked to identify ungrammatical sentences and re-write them correctly; (2) an oral interview with a native speaker of English, focusing on the participants' field of study and plans for the future; and (3) an oral narration task where the participants were asked to look at a sequence of events on a video screen and narrate a story to a non-native listener. Their analyses showed that articles were produced with less accuracy in the grammaticality judgment task and far more accurately in the oral narration task. The scholars explained that "effective story-telling requires that the narrator keeps track over time of persons and objects important to the story-line" (p. 34). Indeed, the accuracy of using the in $[+\mathrm{SR},+\mathrm{HK}]$ contexts was greater in the narration task than in the interview task.

More recently, Robertson (2000) worked with 18 speakers of Chinese origin, who were postgraduate students at a major university in the UK with an advanced level of proficiency. They took part in a collaborative problem-solving task. The analyses showed an overall rate of $78 \%$ suppliance of articles in obligatory contexts. With regard to the remaining $22 \%$ of the contexts, Robertson (2000) claimed that many of these instances can be attributed to the difficulty associated with moving from a grammar of Chinese which is discourse-oriented to a grammar of English which is syntax-oriented. In a discourse-oriented language like Chinese, certain grammatical features such as definiteness, number and tense are not marked overtly when the relevant information can be recovered from the context. In contrast, in a syntax-oriented language like English, these grammatical features must receive overt morphosyntactic realization. As such, Chinese learners of English seem to produce article-related errors as they are in the process of transitioning into a syntax-oriented grammar.

A number of studies that examined article use in oral language have suggested that a great deal of article-related errors are indicative of traces of L1 transfer, especially when learners' L1s do not employ articles as English does. For instance, these learners tended to omit articles in obligatory contexts. They also showed a tendency of over-using the in instances in which $a$ was required. In addition, the oral data on L2 article use seem to suggest that the definite article is acquired before the indefinite article. In the following section, a review of research on the written production of articles by L2 learners of English is provided.

\subsection{L2 Article Production in Written Discourse}

In the field of SLA, several studies were conducted to examine article use in L2 writing. For instance, Lee (1997) carried out a quantitative analysis of the frequency of English article deletion in compositions by Korean learners of English as a Foreign Language (EFL). In the study, 49 university freshmen in Korea were asked to write a short essay. The result showed that the learners did not delete articles with high frequencies. The researcher suggested that the low deletion rate might be attributed to the fact that it was a writing task that allowed learners time to correct their mistakes. 
Park (2006) recruited 33 Korean adult learners of English who were students in the U.S. at the time of the data collection. They were divided into three proficiency groups. The participants carried out a written fill-in-the-article task and produced a written essay on the topic of things they liked about living in the U.S. The purpose of the study was to investigate if levels of English language proficiency could predict Korea learners' accuracy in the use of English articles. The results suggest that the overuse of the zero article was the most frequent and distinct characteristics of Korean learners' use of articles and the proficiency levels did not seem to affect the overuse of the zero article. Similar to Lee's (1997) findings, Park (2006) also demonstrated the Korean learners' tendency to omit the required articles in written discourses.

Whereas the first two studies were mainly descriptive of the learners' interlanguage, Ekiert (2010) employed a cognitive approach to investigate if and how learners who do not formally mark definiteness in their L1s express definiteness and its meanings when they use articles in writing tasks. The result showed that article use in first-mention contexts for specific referents was shown to be particularly problematic, which indicated that the participants' article use was often conditioned by speaker-centric assumptions about the status of referents. Ekiert suggested that "the notion of familiarity, understood as the assessment of what is known to the hearer, may need to be isolated as one of the potential suspects responsible for the difficulty that English articles pose for L1 Slavic learners" (p. 2). Ekiert's study reported that speakers of L1s that do not have an article system may experience difficulty in learning to use English articles because the analysis involves the restructuring of conceptual distinctions with regard to the notion of definiteness and its instantiation in the form of articles.

Several studies examined written production of articles to explore how learners use articles in writing. Lee (1997) and Park (2006) suggested that L2 learners do not seem to omit articles as frequently as expected and proficiency levels do not seem to condition article omission errors. Meanwhile, Ekiert (2010) argued that L1 Slavic learners had difficulty in accurate written production of articles mainly because they did not consider the readers' perspectives in determining the definite status of noun referents. However, there has not been much research that compares how the same learners would use articles differently in speaking and writing to investigate levels of explicit and implicit knowledge involved in article production, a gap identified in the review of previous studies.

\subsection{Research Questions}

For the purpose of addressing the gap that has been identified in the review of literature, the present study examined how Korean learners of English at different proficiency levels produced articles in speaking and writing. In particular, the study attempted to address the following research questions:

1. How are the patterns in the use of articles different in speaking as compared to writing?

2. How are the effects of discourse types different according to English language proficiency levels?

3. How are the effects of discourse types different on the definite article as compared to the indefinite article?

\section{Method}

\subsection{Participants}

The target sample size for this study was 10 beginners, 10 intermediates, and 10 advanced learners of English from Korean L1 background. Initially, 44 Korean speakers of English in their 20s were recruited, from which 30 participants were finally selected for the study based on the proficiency assessment results. Since proficiency was a key external variable in this cross-sectional study, a detailed proficiency evaluation process was employed to determine their proficiency levels. Specifically, three instruments were used: a Cloze test to measure overall linguistic competence, a sociolinguistic interview to assess oral language proficiency and obtain background information on English language learning, and a writing task to triangulate the writing proficiency with the oral and linguistic competence. Group means and standard deviations of the Cloze scores, ages of arrival in the U.S., and lengths of stay in the U.S. are summarized in Appendix A.

\subsection{Instruments}

In order to investigate how Korean learners of English employed articles in oral and written production, narrative tasks were implemented. Free constructed responses such as oral narratives require the production of language with a communicative purpose. Thus, free production tasks require a language user to focus on meaning rather than form. Further, a story can provide a realistic context for grammatical forms while engaging in meaning. While speech is produced spontaneously, writing allows more time to possibly monitor production. Thus, it is generally expected that grammatical accuracy is higher in writing than in speaking, but this hypothesis has not been empirically tested with regard to English articles. Since the participants were not informed that articles were a target linguistic feature of the study, the amount of attention they directed to accurate production of 
articles would be dependent on the level of sensitivity and awareness they have about the article system.

To elicit oral narratives, each participant was asked to tell a personal story that was the most important or memorable to the participant. As the participants in this study speak English as their second language, it might not have been easy for them to produce a large amount of language, particularly for beginner level participants. As such, personal stories were most likely to engage the participants and elicit most language from them. There was no time limit imposed on this task. The participants' oral narratives were digitally audio-recorded for storage and transcribed for analysis.

Immediately after producing an oral narrative, each participant engaged in a writing task. Instead of providing a separate topic for writing, the participants were asked to create written narratives of the stories that were already narrated orally. For the written narrative, each participant was provided with a laptop computer, where spell check and grammar check functions were disabled. However, paper and pencils were also available in case the participant wishes to write on paper. Dictionaries were not allowed. As mentioned earlier, the purpose of collecting written narratives was to compare patterns of article use between speaking and writing. It is generally assumed that learners are afforded more time and attention to linguistic features in writing because writing is a more planned activity. Therefore, time limits were not placed on this task.

\subsection{Data Analysis}

The focus of analyses was to examine and compare patterns of article use in the oral and written production according to proficiency levels. In the analyses of oral and written narratives, the first step was to identify all the noun phrases (NPs), excluding proper nouns (i.e., names of people and places) and pronominal phrases (e.g., $\underline{S h e}$ was excited to see her mother.) which do not take articles. The variables which were examined were accuracy of article use and the category of NP contexts. After the required articles and produced articles for all the NPs were coded, accuracy in article use for the NPs was coded. The produced article was coded accurate if it was identical to the required form. However, it is important to note that depending on the context, there may be more than one grammatically accurate determiner choice for a given pre-nominal position. As long as a form in a pre-noun position was grammatically accurate, it was coded as accurate. In this study, only the overt articles (i.e., the and $a$ ) were included in the analyses.

Next, types of NP contexts were identified and coded. The two types of NP contexts for the definite article used in this study were informed by Hawkins (1978). Using the notion of a shared set, Hawkins (1978) classified usage types of the definite article into four categories: (a) anaphoric use, (b) immediate situation and visible situation use, (c) larger situation use based on shared general knowledge, and (d) associates of the referent. Among the four categories, the anaphoric use is most frequent in narratives to maintain referential coherence. Also, the rule of article use for anaphoric references (i.e., the use of the for subsequent-mentions of previously introduced referents) is well-known to most ESL learners as this rule is included in sections on article use in ESL textbooks. For these reasons, it was assumed that the anaphoric use of the definite article would be easier for Korean learners of English compared to the other usage. As such, NP contexts for the in this study were divided into two categories. The anaphoric definite contexts refer to second and subsequent mentions of a referent that has been previously introduced in the discourse. The associative definite contexts refer to the other three uses of the and include instances in which the definiteness of a noun referent is determined by contextual factors such as shared knowledge and post-adjectival modifications.

With regard to the indefinite article, NP contexts in which the indefinite article $a$ is used can be divided into two: referential indefinite contexts and non-referential indefinite contexts. Following Ekiert (2010), referential indefinite contexts are associated with the first mention of a referent that is specific yet unknown to the hearer as in I bought a gift for you. Non-referential indefinite contexts refer to instances in which a noun referent does not refer to any specific entity as in I feel lonely. I need a friend.

After the initial coding by the researcher, an inter-rater reliability check was carried out by outside rater who was a native speaker of English and a Ph.D. student in the language education program. There was a $94.8 \%$ agreement between the researcher and the rater ( $N=417$ agreed out of $440 \mathrm{NPs})$. To ensure a statistically reliable degree of agreement, Cronbach's $\alpha$ was calculated, which was .919. After all the coding was complete, the statistical program of SPSS was used to carry out statistical analyses. Descriptive statistics were conducted to identify patterns of article use according to proficiency levels between the two discourse types.

\section{Results and Discussion}

\subsection{The Beginner Group's Patterns of Article Use in Oral and Written Narratives}

This section discusses how beginners used articles in oral narratives and written narratives. First, the accuracy in 
the use of articles by the beginner group is compared between the two discourses to understand the relationship between article accuracy and production mode.

Table 1. Accuracy in the use of articles by the beginners in oral and written narratives

\begin{tabular}{lll}
\hline Discourse & Accurate use of the & Accurate use of $a$ \\
\hline Oral Narrative & $54.1 \%$ & $27.5 \%$ \\
Written Narrative & $55.9 \%$ & $38.6 \%$ \\
\hline
\end{tabular}

In Table 1, we find that in general, the beginners employed both articles more accurately in writing than in speaking. This observation supports the hypothesis that articles would be used more accurately in the written text Because writing is a planned discourse and speaking is not, participants seem to have been able to pay more attention to article use in their written narratives. Between the two articles, the same beginners used $a$ much more accurately in writing than in speaking, but they employed the with similar rates of accuracy in speaking and writing. This result suggests that the indefinite article is more challenging for the beginners to produce accurately in spontaneous production compared to the definite article because the accurate production of $a$ involves correct identification of countability and noun numbers of nominal referents.

The beginner group also exhibited different patterns of article use in spoken and written discourses with regard to NP contexts in which the was required. Table 2 shows rates of accuracy in the spoken and written production of the in two NP contexts: anaphoric definite contexts and associative definite contexts.

Table 2. Accuracy in the use of the in two NP contexts across oral and written discourses

\begin{tabular}{lll}
\hline Discourse & Anaphoric definite contexts & Associative definite contexts \\
\hline Oral Narrative & $45.2 \%$ & $63.0 \%$ \\
Written Narrative & $56.9 \%$ & $58.4 \%$ \\
\hline
\end{tabular}

We observe in this table that the beginners' production of the in anaphoric definite contexts was more accurate in the written narratives than the oral narratives $(45.2 \%$ vs. $56.9 \%)$. In writing, all the utterances are available for review. Thus, it may have been less challenging for beginners to recognize anaphoric relationships and employ the for those nominals that had been previously introduced in the discourse.

In the associative definite contexts, the reverse pattern was evident since beginners employed the more accurately in oral narratives when the article was used in associative definite contexts. This finding appears to be contrary to the overall assumption that grammatical structures tend to be produced more accurately in written production than in oral production. Higher accuracy for the in associative definite contexts in oral narratives may be related to L2 learners' tendency to rely on formulaic chunks in speaking for the sake of fluency. Qualitative examination of the oral corpus produced by the beginners seems to suggest the reliance on formulaic language. Further, various instances of the in formulaic expressions fall mostly under the category of associative definite contexts in this study. The following examples are illustrative of such instances of the from beginners' oral narratives.

(1) In the morning, my cousin just drop over there. (B5)

(2) She picked up the phone and then she just said like that. (B5)

(3) One day, I went to the field for training. (B6)

(4) I took the short film for the first time (B10)

As beginners utilized memorized formulaic expressions such as the above examples, they tended to exhibit a more target-like use of the definite article, a possible explanation for the higher accuracy for the in associative definite contexts in oral narratives compared to written narratives.

Next, we examine different patterns of article use in spoken and written production with regard to NP contexts in which $a$ was required. In Table 3, rates of accuracy in the oral and written production of $a$ are shown in two NP contexts: referential indefinite contexts and non-referential indefinite contexts. 
Table 3. Accuracy in the use of $a$ in two NP contexts across oral and written discourses

\begin{tabular}{lll}
\hline Discourse & Referential indefinite contexts & Non-referential indefinite contexts \\
\hline Oral Narrative & $29.0 \%$ & $27.0 \%$ \\
Written Narrative & $46.4 \%$ & $36.8 \%$ \\
\hline
\end{tabular}

As Table 3 shows, beginners produced $a$ more accurately in writing for both NP contexts types for the indefinite article. In referential indefinite contexts, the accuracy for $a$ was $29.0 \%$ in oral narratives but the accuracy was higher at $46.4 \%$ in written narratives. Similarly, the indefinite article was used accurately in $27.0 \%$ of the spoken utterances and, in writing, $36.8 \%$, a higher frequency. Writing seems to provide a more favorable condition for L2 learners to identify contexts that require $a$ and they employ the form with better accuracy. Thus, here too we can observe a consistent pattern of higher rates of accuracy in written discourse.

\subsection{The Intermediate Group's Patterns of Article Use in Oral and Written Narratives}

In this section articles produced by intermediates in oral narratives are compared with those produced in written narratives. As a first step, rates of accuracy in the use of articles are compared between the two modes of language production.

Table 4. Accuracy in the use of articles by the intermediates in oral and written narratives

\begin{tabular}{lll}
\hline Discourse & Accurate use of the & Accurate use of $a$ \\
\hline Oral Narrative & $63.9 \%$ & $34.3 \%$ \\
Written Narrative & $72.2 \%$ & $70.8 \%$ \\
\hline
\end{tabular}

Similar to the beginner group, in general, the intermediates produced articles more accurately in writing than in speaking. The discourse effect was much more evident in the use of the indefinite article $a$. Specifically, the same participants employed $a$ in written narratives with an accuracy nearly twice higher than that seen in oral narratives. This finding suggests that the intermediates have sufficient explicit knowledge to monitor their article use when they are given time and cognitive attention to review their writing. With the accuracy in the use of $a$ in more than $70 \%$ of the instances in their written narratives, this finding point to conscious knowledge of English articles possessed by the intermediates as manifested in higher accuracy in writing. Also, the findings could suggest that the intermediates' knowledge of English articles is not completely implicit as their accuracy in the use of articles is still considerably lacking in oral production, in particular for the indefinite article.

We now turn our attention to the effect of different NP contexts on article use in two different discourses. Table 5 presents rates of accuracy for the in two definite NP contexts in the oral and written narratives.

Table 5. Accuracy in the use of the in two NP contexts across oral and written discourses

\begin{tabular}{lll}
\hline Discourse & Anaphoric definite contexts & Associative definite contexts \\
\hline Oral Narrative & $58.5 \%$ & $67.0 \%$ \\
Written Narrative & $84.8 \%$ & $69.1 \%$ \\
\hline
\end{tabular}

In the above table, we observe a dramatic increase in accuracy with which the was produced in anaphoric definite contexts across the discourses, while the accuracy in the use of the was similar between writing than speaking. For example, in oral narratives, the was employed accurately in $58.5 \%$ of the anaphoric definite contexts, but the accuracy increased to $84.8 \%$ in the written narratives, a remarkably high rate of accuracy. The following examples were produced by one intermediate participant (I6) in the oral and written narratives.

(5) let me call, like, one of doctor that I know, so we went to * doctor's office (ON)

(6) She called one doctor she's known and we went to the doctor's office (WN)

In examples (5) and (6), the underlined phrase was produced without an article in the oral narrative and with the definite article in the written narrative. This is one of many instances in which intermediates successfully kept 
track of anaphoric references and employed the definite article appropriately. This finding suggests that intermediates have an understanding of the role of the definite article in anaphoric expressions. The learners, however, might not have spontaneous access to this knowledge in spontaneous speech, thereby resulting in lower accuracy in the anaphoric use of the in oral narratives. Thus, the intermediates' explicit knowledge of articles seems to be more developed than the implicit knowledge.

Next, we examine whether or not article accuracy was affected by the discourse of language production according to NP contexts for the indefinite article.

Table 6. Accuracy in the use of $a$ in two NP contexts across oral and written discourses

\begin{tabular}{lll}
\hline Discourse & Referential indefinite contexts & Non-referential indefinite contexts \\
\hline Oral Narrative & $31.3 \%$ & $35.8 \%$ \\
Written Narrative & $66.7 \%$ & $73.0 \%$ \\
\hline
\end{tabular}

In both types of indefinite contexts, accuracy was higher in the written production. The accuracy in the use of $a$ in referential indefinite contexts was $31.3 \%$ in speaking and much higher at $66.7 \%$ in writing. Similarly, $a$ was produced accurately in $35.8 \%$ of the non-referential indefinite contexts in speaking and $73 \%$ in writing. These differences seem to reflect the overall tendency that target-like use of articles was more evident in the written narratives. Much like the beginner group and as hypothesized, the written production of articles up to this point has tended to be more target-like than the production of articles in oral discourse.

\subsection{The Advanced Group's Patterns of Article Use in Oral and Written Narratives}

This section addresses the effect of L2 production genres on article accuracy in the advanced group. First, rates of accuracy for article use are compared between the oral and written narratives in Table 7.

Table 7. Accuracy in the use of articles by the advanced learners in oral and written narratives

\begin{tabular}{lll}
\hline Discourse & Accurate use of the & Accurate use of $a$ \\
\hline Oral Narrative & $76.2 \%$ & $55.1 \%$ \\
Written Narrative & $76.1 \%$ & $75.8 \%$ \\
\hline
\end{tabular}

In Table 7, we first note that the definite article was employed with similar rates of accuracy in writing and speaking. The observed stability in the use of the suggests that the participants in the advanced group have achieved a high level of proficiency with regard to the definite article. Conversely, the use of $a$ tended to be affected by the discursive modality in the advanced group in much similar ways to those reported for the beginner and the intermediate groups. Thus, we may infer that conceptual changes involving the indefinite article may be delayed compared to the definite article for the advanced group.

We now examine the effect of discourse with regard to article accuracy and the variable of NP contexts.

Table 8. Accuracy in the use of the in two NP contexts across oral and written discourses

\begin{tabular}{lll}
\hline Discourse & Anaphoric definite contexts & Associative definite contexts \\
\hline Oral Narrative & $84.1 \%$ & $79.6 \%$ \\
Written Narrative & $73.6 \%$ & $80.3 \%$ \\
\hline
\end{tabular}

When the was required in anaphoric definite contexts for subsequent mentions, the form was produced more accurately in speaking than in writing. One possible explanation for this pattern is that an oral narrative task poses more communicative pressure on the narrator to maintain referential coherence. For instance, Tarone and Parrish (1988) compared article use in three different tasks: a written grammaticality judgment task, an oral interview, and an oral narration. The researchers found that the in anaphoric definite contexts was used most accurately in the oral narrative task. Similarly, the advanced participants in this study employed the more accurately in anaphoric definite contexts when the form was produced in oral narratives. In turn, rates of accuracy in the use of the in associative definite contexts were similar between the spoken and written discourses, 
an indication of stability in the use of the in these contexts.

Finally, the accuracy with which $a$ was used is compared between the two genres of production according to two indefinite NP contexts.

Table 9. Accuracy in the use of $a$ in two NP contexts across oral and written discourses

\begin{tabular}{lll}
\hline Discourse & Referential indefinite contexts & Non-referential indefinite contexts \\
\hline Oral Narrative & $55.8 \%$ & $55.6 \%$ \\
Written Narrative & $68.3 \%$ & $77.5 \%$ \\
\hline
\end{tabular}

In both indefinite NP contexts, $a$ was used more accurately in written narratives than oral narratives. This tendency was observed in the other proficiency groups and may be related to the benefits of a written task, including more time to review and review L2 production and more attention to grammatical accuracy by utilizing conscious knowledge of articles, among many other aspects of English.

\subsection{Discussion}

With regard to article accuracy between oral and written discourses, all proficiency groups produced articles more accurately in writing than in speaking, which was an expected finding. Compared to the oral narrative task, the written narrative task may have offered advantages to the participants in terms of fluency, accuracy and complexity in the output. In particular, research has shown that accuracy is enhanced with on-line planning (i.e., within-task planning) as opposed to pre-task planning (Ellis \& Yuan, 2004; Meraji, 2011). For instance, Ellis and Yuan (2004) studied the effects of three types of planning conditions (pre-task planning, unpressured on-line planning, and no planning) on written narratives produced by Chinese learners of English. The results showed that unpressured on-line planning provided better opportunities for monitoring, thus leading to increased accuracy in the written texts. Likewise, in this present study, the participants were instructed to spend as much time as they liked in producing written narratives. Therefore, the overall accuracy in the use of English articles was higher in the written narratives compared to the oral narratives.

However, the availability of time and resources for reflection and revision of the written production may not have the same positive effect on learners of English with respect to accurate article production. That is, with sufficient knowledge of the English article system to monitor output, the L2 writer may be able to avoid making article errors. Yet, if the writer lacks awareness and understanding of how articles are used in English, the affordance of time and the advantage of the written discourse may not be useful. This can possibly explain why beginners still produced both article forms with low rates of accuracy in the written discourse. The results are indicative of the fact that the beginners have not yet developed sufficient awareness of the English article system to discern contexts for articles and produce them accurately. According to the Noticing Hypothesis, "learners must make conscious comparison between their own output and target language input" (Schmidt, 2010, p. 724) in order to overcome errors. This idea of "noticing the gap" originated from the scholar's own experiences in learning Portuguese in Brazil. Schmidt remarked that frequent correction for his grammatical errors had no effect in many cases because he was unaware that he was being corrected. In this study, the beginners may have not been fully aware of the article system and thus failed to make a conscious comparison between their own writing and the target language to prevent misuses.

Between the two overt articles (the and $a$ ), the indefinite article was found to have been affected more by the different discourse types than the definite article. In all proficiency groups, the difference in accuracy rates of $a$ between oral and written narratives was considerably larger than the difference in accuracy rates of the between the two discourses. The greater effect of discourse types on the accurate use of $a$ may be attributed to the complexity of the indefinite article. The accurate use of $a$ in English requires a consideration of a multitude of factors that are semantic, pragmatic, contextual, and discursive. For instance, in the binary schema of English articles, Master (1990) suggested that speakers of English need to make three distinctions in order to produce $a$ accurately: definiteness, countability, and noun number of NPs. Simultaneous determination of the three distinctions is a complicated task because each of these distinctions is not inherent in lexical items but highly dependent on a given discourse context. As such, Korean learners of English may experience difficulty in accurately producing $a$ in a spontaneous speech.

Furthermore, the acquisition order of articles may be related to the lower accuracy rates with which $a$ was produced in spontaneous oral discourse than the. With regard to the order of acquisition of the two articles, 
several studies (e.g., Huebner, 1983; Master, 1997; Parrish, 1987; Thomas, 1989) have suggested early integration of the into the learner's interlanguage before $a$. As the participants' understanding and acquisition of $a$ is not as advanced as that of the the spontaneous production of $a$ in oral narratives was more challenging to the participants than in written narratives. In this regard, it is worth noting that even the advanced speakers' performance with the indefinite article was considerably affected by the constraints associated with oral discourse. Indeed, they produced $a$ accurately in only $55 \%$ of the instances in which this article was required in their oral narratives. The different patterns of using the two articles between oral and written narratives observed in this study provide further support of the directionality in L2 article acquisition that has been reported in the field.

With respect to the development of implicit and explicit knowledge of articles along with the proficiency continuum, we note that a considerable improvement in the accurate use of $a$ was observed in the intermediate learners' written narratives. The noticeable increases in the accuracy with which the intermediates employed articles in writing may be indicative of their sensitivity to rules associated with English articles. Thus, they are able to better reflect on article use. Even though the intermediates' implicit knowledge of English articles that was manifested in their oral narratives may not have reached a level of stability, they seem to have acquired a sufficient level of explicit knowledge on how articles are supposed to be used in English. As Ellis (1994) explained, explicit knowledge is what language learners use to monitor for grammatical accuracy in their language production. This kind of explicit knowledge can later become part of the implicit knowledge as they continue on their language learning. While the intermediate group still exhibited a gap between their implicit knowledge of articles manifested in the oral narratives and the explicit knowledge of articles revealed in more accurate production of articles in the written narratives, the advanced group seems to have stabilized in their use of articles across two discourse types.

\subsection{Pedagogical Implications}

The findings of the study have pedagogical implications that can contribute to improving teaching practices of English articles to L2 learners of English. In general, ESL/EFL teachers have not been well equipped with effective article instruction strategies. ESL teachers may find it difficult to explain various uses of articles in an explicit and coherent manner to their students. In White's (2010) survey, many experienced ESL teachers expressed a lack of confidence and a sense of frustration with regard to teaching articles. This section discusses pedagogical implications of the study in hopes of addressing challenges experienced by English language teachers.

First of all, the results suggest that L2 learners of English tend to produce articles more accurately in the written mode thanks to the availability of time and cognitive attention towards grammatical accuracy. Thus, teachers can utilize writing activities to bring learners' attention to the English article system. This approach is beneficial in that writing can help lower anxiety of learners by reducing pressure to perform spontaneously while encouraging learners to use articles in a communicatively meaningful context. Indeed, Ellis, Sheen, Murakami and Takashima (2008) demonstrated the effectiveness of written corrective feedback to improve article accuracy among L2 learners. The use of writing in article instruction would be most beneficial for learners at the beginning levels.

The study revealed that the intermediate learners have sufficient explicit knowledge of English articles to monitor and produce articles accurately in writing but their knowledge is not yet implicitly incorporated in their L2 grammar, especially with regard to the indefinite article. Here, various oral activities can be designed to help intermediate learners improve article accuracy in their speech as well as in their writing. For instance, Pica (1983) proposed that sample dialogues can be provided to show how articles are used for various referential expressions and that learners can create similar dialogues on their own while carrying out communicative tasks.

Between the two articles, the indefinite article seems to require more time and attention in the classroom. The results of this study show that the indefinite article was acquired later than the definite article and this form was affected more by the cognitive constraints in spontaneous oral production. As such, ESL teachers can design separate lessons dedicated to the use of $a$ by focusing on the noun number and countability aspects of nouns that condition the use of the indefinite article. As Akakura (2009) showed in a study on the effects of explicit instruction on the explicit and implicit knowledge of articles, explicit instructions that bring learners' attention to particular uses of the indefinite article can contribute to improving the overall knowledge of the English articles, which in turn may promote a more accurate production of articles in both speech and writing.

\section{Conclusion}

The result of the study shows that learners at all levels of proficiency used articles more accurately in writing than in speech. This finding suggests that L2 speakers of English are generally affected by cognitive processing 
constraints inherent in spontaneous L2 production. In a spoken discourse, pressure to produce L2 in a spontaneous manner tends to constrain cognitive resources of the learner and lead to performance-related errors. Thus, as Trenkic (2009) maintained, determining all aspects of NPs in a particular discourse context for the accurate production of articles in L2 oral speech may have imposed increased cognitive challenges to L2 speakers in this study.

The study also reveals that compared to the definite article, the accurate production of the indefinite article was affected more by cognitive processing constraints. In all proficiency groups, the effects of discourse types on article production were greater in the case of the indefinite article than the definite article. Another finding was that the intermediate learners were at a level in which qualitative changes seem to take place with regard to English article acquisition as their explicit knowledge of articles seems to be more advanced and developed than their implicit knowledge of articles.

There are limitations to the present study. The first of these is the limitation concerned with the way the narrative production tasks were designed. In the current study, participants were allowed to narrate any stories they wanted. As such, the content of the narratives collected for data analyses varied greatly. As a wide range of nominal referents were produced in a variety of stories, a comparison of article use for the same NPs across participants was not possible. It would be interesting to use the same prompt such as a short silent film to elicit article production data. Then, there could be some level of control over the content of the oral and written data. This way, the same nominal referents that appear in the movie could be tracked for article use among different proficiency levels and how article use differed between speaking and writing.

Also, the present study recruited Korean learners of English who were living in the U.S. at the time of the data collection. That is, this population has been exposed to articles used by native English speakers in various situations. The current study did not examine patterns of articles used by learners who are in Korea (i.e., EFL learners). It can be assumed that sources of input for article use in the EFL context would be mostly textbooks and a limited amount of usage input from classroom discourses. Therefore, a comparison of article use between Korean learners of English in the U.S. and Korean learners of English in Korea would provide an opportunity to investigate relationships between patterns of article use and the quality of input regarding authentic article use.

\section{References}

Akakura, M. A. (2009). Effect of explicit instruction on implicit and explicit second language knowledge: An empirical study on English article acquisition. Unpublished Ph.D. Dissertation, The University of Auckland.

Butler, Y. G. (2002). Second language learners' theories on the use of English articles. Studies in Second Language Acquisition, 24, 451-480. http://dx.doi.org/10.1017/S0272263102003042

Ekiert, M. B. (2010). Articles as expressions of definiteness in L2 English of Slavic speakers. Unpublished Ph.D. Dissertation, Columbia University.

Ellis, R. (1994). The study of second language acquisition. Oxford, UK: Oxford University Press.

Ellis, R., Sheen, Y., Murakami, M., \& Takashima, H. (2008). The effect of focused and unfocused written corrective feedback in an English as a foreign language context. System, 36, 353-371. http://dx.doi.org/10.1016/j.system.2008.02.001

Ellis, R. \& Yuan, F. (2004). The effects of planning on fluency, complexity, and accuracy in second language narrative writing. Studies in Second Language Acquisition, 26, 59-84. http://dx.doi.org/10.1017/S0272263104261034

Hawkins, J. A. (1978). Definiteness and indefiniteness. London: Croom Helm.

Huebner, T. (1979). Order-of-acquisition vs. dynamic paradigm: A comparison of method in interlanguage research. TESOL Quarterly, 13, 21-28. http://dx.doi.org/10.2307/3585972

Lee, H. (1997). English article deletion in Korean EFL learners' compositions. Working Papers in Educational Linguistics, 13(2), 41-50.

Liu, D., \& Gleason, J. L. (2002). Acquisition of the article the by nonnative speakers of English: An analysis of four nongeneric uses. Studies in Second Language Acquisition, 24, 1-26. http://dx.doi.org/10.1017/S0272263102001018

Master, P. (1990). Teaching the English articles as a binary system. TESOL Quarterly, 24(3), 461-478. http://dx.doi.org/10.2307/3587230

Master, P. (1997). The English article system: Acquisition, function, and pedagogy. System, 25, $215-232$. 
http://dx.doi.org/10.1016/S0346-251X(97)00010-9

Meraji, S. R. (2011). Planning time, strategy use, and written task production in a pedagogic vs. a testing context. Journal of Language Teaching and Research, 2(2), 338-352. http://dx.doi.org/10.4304/jltr.2.2.338-352

Mizuno, M. (1999). Interlanguage analysis of the English article system: Some cognitive constraints facing the Japanese adult learners. International Review of Applied Linguistics in Language Teaching, 37(2), 127-153.

Park, S. B. (2006). The acquisition of written English articles by Korean learners. Unpublished Ph.D. Dissertation, Southern Illinois University.

Parrish, B. (1987). A new look at methodologies in the study of article acquisition for learners of ESL. Language Learning, 37, 361-383. http://dx.doi.org/10.1111/j.1467-1770.1987.tb00576.x

Pica, T. (1983). The article in American English: What the textbooks don't tell us. In N. Wolfson, \& E. Judd (Eds.), Sociolinguistics and language acquisition (pp. 222-233). London: Newbury House Publishers.

Robertson, D. (2000). Variability in the use of the English article system by Chinese learners of English. Second Language Research, 16(2), 135-172. http://dx.doi.org/10.1191/026765800672262975

Schmidt, R. (2010). Attention, awareness, and individual differences in language learning. In W. M. Chan, S. Chi, K. N. Cin, J. Istanto, M. Nagami, J. W. Sew, T. Suthiwan, \& I. Walker (Eds.), Proceedings of CLaSIC 2010 (pp. 721-737). Singapore: National University of Singapore, Center for Language Studies.

Tarone, E., \& Parrish, B. (1988). Task-related variation in interlanguage: The case of articles. Language Learning, 38(1), 21-44. http://dx.doi.org/10.1111/j.1467-1770.1988.tb00400.x

Thomas, M. (1989). The acquisition of English articles by first- and second-language learners. Applied Psycholinguistics, 10, 335-355. http://dx.doi.org/10.1017/S0142716400008663

Trenkic, D. (2007). Variability in second language article production: Beyond the representational deficit vs. processing constraints debate. Second Language Research, 23(3), 289-327. http://dx.doi.org/10.1177/0267658307077643

Trenkic, D. (2009). Accounting for patterns of article omissions and substitutions in second language production. In M. Garcia Mayo, \& R. Hawkins (Eds.), Second language acquisition of articles (pp. 115-146). Amsterdam: John Benjamins.

White, B. (2010). In search of systematicity: A conceptual framework for the English article system. Unpublished Ph.D. Dissertation, Michigan State University.

White, L. (2003). Fossilization in steady state L2 grammar: Persistent problems with inflectional morphology. Bilingualism: Language and Cognition, 6(2), 129-141. http://dx.doi.org/10.1017/S1366728903001081

Young, R. (1996). Form-function relations in articles in English interlanguage. In R. Bayley, \& D. R. Preston (Eds.), Second language acquisition and linguistics variation. Philadelphia, PA: John Benjamins B.V.

Zdorenko, T., \& Paradis, J. (2008). The acquisition of articles in child second language English: Fluctuation, transfer or both? Second Language Research, 24(2), 227-250. http://dx.doi.org/10.1177/0267658307086302

\section{Appendix A}

Background information of the participants according to proficiency groups

\begin{tabular}{lllll}
\hline $\begin{array}{l}\text { Proficiency } \\
\text { group }\end{array}$ & $N$ & $\begin{array}{l}\text { CLOZE score } \\
\text { (perfect }=63)\end{array}$ & Age of arrival in the U.S. & $\begin{array}{l}\text { Mean length of stay in the } \\
\text { U.S. in Years }\end{array}$ \\
\cline { 2 - 5 } & & Mean $(S D)$ & Mean $(S D)$ & Mean $(S D)$ \\
\hline Beginner & 10 & $19.9(8.7)$ & $23.7(1.76)$ & $0.95(0.82)$ \\
Intermediate & 10 & $31.7(3.12)$ & $22.2(2.34)$ & $2.32(1.64)$ \\
Advanced & 10 & $38.0(5.18)$ & $15.6(3.16)$ & $7.35(2.40)$ \\
\hline
\end{tabular}

\section{Copyrights}

Copyright for this article is retained by the author(s), with first publication rights granted to the journal.

This is an open-access article distributed under the terms and conditions of the Creative Commons Attribution license (http://creativecommons.org/licenses/by/3.0/). 